\title{
Modeling and simulation analysis of propyl-thiouracil (PTU), an anti-thyroid drug on thyroid peroxidase (TPO), thyroid stimulating hormone receptor (TSHR), and sodium iodide (NIS) symporter based on systems biology approach
}

\author{
Manish Kumar Gupta • Krishna Misra
}

Received: 23 October 2012/Revised: 10 January 2013/Accepted: 15 January 2013/Published online: 13 February 2013

(C) Springer-Verlag Wien 2013

\begin{abstract}
The aim of metabolic modeling was to understand the cause effect interaction and reliance linked with the complex interactions of biological networks and molecular systems. Drugs that therapeutically modulate the biological processes of disease are often developed with limited knowledge of the underlying complexity of their specific targets. The robustness for systemic modulating behavior of thyroid hormone secretion during the course of different time unit simulation is explained in this study. In this work, a computational model has been developed which mimics the in vivo simulation. The model was constructed with the help of cell designer 4.1 used for analyzing the effect of perturbed amount of drugs at 0.1 , $0.5,1.0,1.5,2.0,2.5,3.0$ amounts as a unit, targeting Thyroid Peroxidase (TPO), Thyroid Stimulating Hormone Receptor (TSHR), and Sodium Iodide Symporter (NIS). The rate kinetic equations were defined with each reaction to simulate the molecular species dynamic behavior. The modulating behavior of thyroid hormone secretion was analyzed by the process of activation and inactivation states of TPO, TSHR, and NIS at various amounts of drugs.
\end{abstract}

Electronic supplementary material The online version of this article (doi:10.1007/s13721-013-0023-0) contains supplementary material, which is available to authorized users.

\section{K. Gupta}

Department of Bioinformatics, University Institute of Engineering and Technology, Chhatrapati Shahu Ji Maharaj University, Kanpur, UP 208024, India e-mail: manish.kumar.gupta@gmail.com

K. Misra $(\bowtie)$

Centre of Biomedical Magnetic Resonance,

Sanjay Gandhi Post-Graduate Institute of Medical

Sciences Campus Raebareli Road, Lucknow 226014, India

e-mail: krishnamisra@hotmail.com
Obtained results explain suitably the entire observable fact of the drug effects and are capable to proceed in response to the perturbations of the natural cell. TSHR was found as the most potent molecular therapeutic target in this study.

Keywords Systems biology - Metabolic modeling · Integrated pathways $\cdot$ Simulation

\section{Introduction}

Human body shows differential behaviors with homeostasis perturbation for over and under secretion of hormones (Chu et al. 2009; Diamanti-Kandarakis et al. 2009). This characterizes often the main hurdle to find out a competent pharmacological treatment against autoimmune thyroid disorder, which results in immune system attacks by body's own thyroid gland. Autoimmune thyroid disorder is an organspecific target (Swain et al. 2005). Genetic, environmental exposures, and various endogenous factors are responsible for initiating the autoimmune thyroid disorder (Davies et al. 2012; Brent 2010; Weetman 2003). It is reported that thyroid hormones (THs), triiodothyronine $\left(\mathrm{T}_{3}\right)$ and thyroxin $\left(\mathrm{T}_{4}\right)$, show the strong association between hyperthyroidism and high energy expenditure (EE) in human (Klieverik et al. 2009). The hypophysiotropic thyrotropin-releasing hormone (TRH), as a metabolic sensor, is regulated at multiple levels to control thyroid function and metabolism (Eduardo 2010; Hollenberg 2008; Wilding 2002). The structure of $\mathrm{T}_{3}, \mathrm{~T}_{4}$, and PTU is shown in Fig. 1.

Thyroid-stimulating hormone (TSH) and receptor TSHR (Farid and Szkudlinski 2004) are main proteins in the regulation of thyroid function. Human TSHR (hTSHR) is measured to be the foremost autoantigen in autoimmune hyperthyroidism in case of Graves's disease (Vlase et al. 
Fig. 1 Structure of a Triiodothyronine $\left(\mathrm{T}_{3}\right)$ Thyroxin $\left(\mathrm{T}_{4}\right)$, and b Propylthiouracil

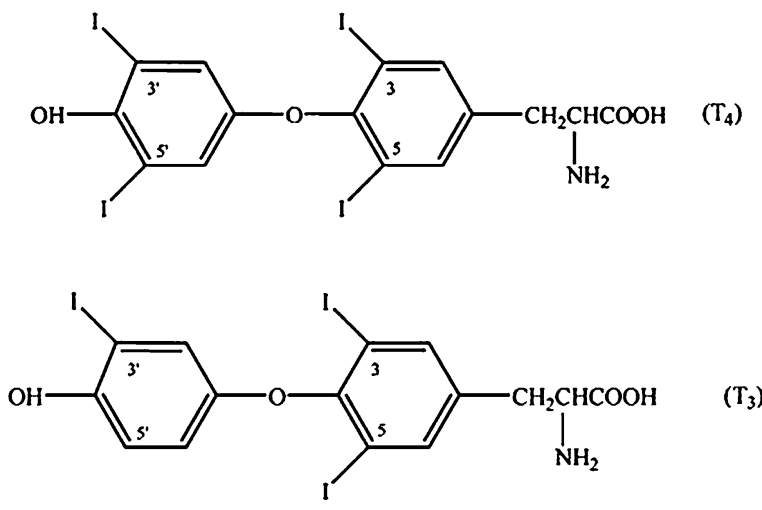

(a)<smiles>CCCc1c[nH]c(=S)[nH]c1=O</smiles>

(b)
1998). Inhibitors that stop the actions of TSHR-stimulating immunoglobulins could be useful for the study and treatment of Graves' disease for which limited therapy exists at present (Szkudlinski et al. 2002). It was found that small molecule inhibitors may serve as a lead compound with therapeutic potential that target TSHR in patients suffering from hyperthyroidism (Neumann et al. 2009, 2010; Chen et al. 2009). Such chemical species could be able to modulate spontaneous fluctuations between active and inactive states.

TPO is an important enzyme for thyroid hormone biosynthesis and major source for an autoantigen in thyroid disorder (Ruf and Carayon 2006; McLachlan and Rapoport 2007). It is usually connected to Hashimoto's thyroiditis (Chardès et al. 2002). The presence of high levels of antibodies to TPO is useful in diagnosis of the disease (McLachlan and Rapoport 2000; Chardès et al. 2002). TPO cooperates in iodination of tyrosyl residues in thyroglobulin and other proteins (Ruf and Carayon 2006; Kessler et al. 2008). TPO is excited by TSH and inhibited by propylthiouracil (PTU) and methimazole (MMI) (Roy and Mugesh 2008).

NIS is a transmembrane glycoprotein that participates in the regulation $\mathrm{Na}^{+} / \mathrm{I}^{-}$gradient and transports two sodium ions $\left(\mathrm{Na}^{+}\right)$for each iodide ion $\left(\mathrm{I}^{-}\right)$into the cell. NIS mediated uptake of iodide ion into follicular cells of the thyroid gland is initial stage for thyroid hormone biosynthesis (Dohán et al. 2003; Riesco-Eizaguirre and Santisteban 2006). Goitre, enlargement of the thyroid, is due to lack of iodide transport inside follicular cells. Mutations in the NIS DNA lead to hypothyroidism and thyroid dyshormonogenesis (Ohye and Sugawara 2010). It was established that perchlorate, pertechnetate and thiocyanate, all anion competitively inhibits the iodide uptake (RiescoEizaguirre and Santisteban 2006).

A model regarding host and pathogen interaction has been developed for simulation analysis to predict the effect of drugs which are resistant to pathogen (Autiero et al. 2009). The integrated pathways help to minimize the effects of external perturbation to whole systems due to its robust properties (Lehar et al. 2008). Every functional species in the pathways is considered as node and linked with other important nodes at defined rate kinetics. Human immune system is very robust to any pathogen attack till certain extent, but sometimes body's own cells do not differentiate it's own and foreign cells that lead to autoimmune disorder and weaken the robustness of defense system (Kitano and Oda 2006; Kim et al. 2009).

The aim of metabolic modelling of thyroid disorder is to come out with a hypothesis based on computational simulation analysis of human disease physiology pathways at various time extents (Butcher et al. 2004; Gupta et al. 2012). The integrated pathways are useful to understand the evolution of disorder, off target and mode of action of drugs as well as in development of new therapeutic drugs (Kell 2006; Singh et al. 2013). It is significant to identify the key properties and parameters which are used to predict the model. Compatibility of amount and type of data used in the model is obligatory to meet the model parameters (Ideker et al. 2001). It is very well established that the active molecules of a living system such as DNA, RNAs, enzymes, receptor, hormones, metabolites, ions, etc., setup is essential for an integrated network to modulate the behavior of metabolic pathways (Autiero et al. 2009). Several In silico comprehensive maps (Oda et al. 2005; Kaizu et al. 2010; Caron et al. 2010; Oda and Kitano 2006; Wu et al. 2010; Calzone et al. 2008) have been developed for disease physiology, dynamic analysis, control mechanism, regulatory element detection for regulation/deregulation, and identification of biomarker for therapy of particular diseases.

Thus, literature supports that three targets (TPO, TSHR, NIS) are quite significant for study due to their medical importance. The molecular interactions and dynamic behavior concerned with the immune system have not been covered so far. In this paper, an effort has been made to describe the integrated pathways of autoimmune thyroid disorder targeting TSHR, TPO, and NIS 
and effect of drug PTU to analyse the dynamics behavior of functional elements. Modeling of thyroid hormone synthesis pathway can help to incorporate experimental information into a coherent representation and to investigate, test, validate, or misrepresent hypotheses about the underlying biological mechanisms (Klipp and Liebermeister 2006). Analyzing the noise effect of experimental data is important for interaction and regulation mechanism of various species involved in simulation effect as well as various network patterns are beneficial for knowledge discovery purposes (Xiang et al. 2012; Bortolussi and Policriti 2012).

\section{Materials and methods}

A comprehensive literature search of various research and review papers related to autoimmune thyroid disorder was done to identify simple and complex proteins, molecules, and ions involved. A graphical notation system for biological networks to express enough information in a clearly visible and explicit way was used (Kitano 2003).

Thyrotropin-releasing hormone receptor signaling pathway was retrieved from panther database (http:// www.pantherdb.org/pathway/pathwayList.jsp) for pathway analysis (Mi et al. 2005). The TSHR, TPO, and NIS network models which include gene, RNA, protein, enzyme, receptor and ions were constructed with CellDesigner ver 4.1 and stored in system biology markup language (SBML) machine-readable model representation format (Funahashi et al. 2007, 2008; Hucka et al. 2004; Funahashi et al. 2003). CellDesigner tool is a process diagram editor for representation of genetic and biochemical pathways. The process diagram is a state transition diagram. Each node signifies state of molecule and complex during construction of pathway. Arrows symbolizes state transition among states of molecule. In the process diagram, a molecule is represented as a state of the note for activation. Stimulation and inhibition of catalysis are characterized as modifier of state transition by a circle-headed line and a bar-headed line, correspondingly. The control panel in CellDesigner is considered to support the operators to simulate directly as well as controlling the amounts and parameters of the species. Calling directly SBML ODE Solver and Copasi, control panel facilitates to specify the particulars of constraints, varying quantity, leading parameter search, and shared simulation with instinctive way. The various individual pathways are able to link with simulation and added analysis program through systems biology workbench (SBW). SBW is an integrated, broker-based, message-passing structure for communication between applications that benefits research in systems biology.
CellDesigner complies with SBW assists the seamless association to SBW-powered simulators. CellDesigner can read and write in SBML layout with rich enriched utilities kept as SBML remarks. SBML is the computerreadable format for demonstrating models of biochemical reaction complexes. SBML is valid to metabolic, cellsignaling, genetic pathways, and many others. CellDesigner also facilitates database connections, intuitive user interface, extensive description of compartments, species, reactions, genes, RNA and proteins, export of images in various formats, support of block diagram, and plug-in development framework.

The simulation behavior of PTU on TSHR, TPO, and NIS was performed with SBML ODE Solver Library (SOSlib) which is both a programming library and a command-line purpose for symbolic and numerical study of a system of ordinary differential equations (ODEs) derived from a chemical reaction network encoded in the SBML. The abilities of SOSlib for sensitivity study allow the operation of effective algorithms for parameter identification. The identification of model parameters and begin settings from noisy experimental facts is a classic ill-posed inverse obstacle and can be articulated in a steady way as a minimization drawback with a data incompatibility and a regularization term.

To simulate the dynamic behavior of biochemical reactions, SBML squeezer 1.3 was used to generate kinetic rate equations for biochemical pathways according to context of each reaction. This approach eases the modeling steps via programmed generation of equation and overcomes the highly error-prone and cumbersome process of manually assigning kinetic equations (Dräger et al. 2008). In relation to the process diagram, it generally remains indistinct as to which state of the reaction the inhibitor or activator interacts with enzyme, substrate or some intermediate complex. SBMLsqueezer uses a generic method for inhibition and activation for various rate laws; for instance, the generalized mass action kinetics or the rather thorough ternary-complex mechanisms. Equation (1) gives the general formula for this prefactor of the preferred rate equation (Klipp and Liebermeister 2006) in the context of suitable kinetics:

$F_{\mathrm{j}}(\vec{S}, \vec{P})=\prod h_{\mathrm{A}}\left(\left[S_{\mathrm{m}}\right], k_{\mathrm{jm}}^{\mathrm{A}}\right)^{W_{\mathrm{jm}}^{+}} h_{1}\left(\left[S_{\mathrm{m}}\right], k_{\mathrm{jm}}^{1}\right)^{W_{\mathrm{jm}}^{-}}$

where $\vec{S}$ and $\vec{p}$ are vectors of the concentrations of all reacting species in the system and parameter values. The matrices are $W^{ \pm}$resultant from the modulation matrix W and comprise the absolute values of all positive or negative elements of this ternary matrix $(-1$ for inhibition, +1 for activation, and 0 for no interaction). The modulation functions read 
$h_{\mathrm{A}}=\left(\left[S_{\mathrm{m}}\right], k_{\mathrm{jm}}^{\mathrm{A}}\right)=\frac{\left[S_{\mathrm{m}}\right]}{k}$

$h_{\mathrm{I}}=\left(\left[S_{\mathrm{m}}\right], k_{\mathrm{jm}}^{\mathrm{I}}\right)=\frac{k_{\mathrm{jm}}^{\mathrm{I}}}{k_{\mathrm{jm}}^{\mathrm{I}}+\left[S_{\mathrm{m}}\right]}$

where $k_{\mathrm{jm}}^{\mathrm{A}}$, activation constant and $k_{\mathrm{jm}}^{\mathrm{A}}$, the inhibitory constant are given in concentration unit of the corresponding species in Eqs. (2) and (3).

When used as a plug-in for CellDesigner it uses the information from the system biology graphical notation (SBGN) representation of all network components. SBMLsqueezer evaluates the Systems Biology Ontology (SBO) annotations to pull out this information. The rate laws that can be created by SBMLsqueezer comprise numerous types of generalized mass action, and comprehensive and generalized enzyme kinetics. Kinetic equations for metabolic reactions include uni-uni Michaelis-Menten kinetics, Irreversible non-modulated non-interacting reactant enzymes, generalized hill equation for uni-uni reactions, bi-uni enzyme reactions, bi-bi enzyme reactions, convenience kinetics and thermodynamics, modular rate laws for enzymatic reactions (Liebermeister et al. 2010). Kinetic equations for gene-regulatory reactions involve various versions of the hill equation, additive network models, S-systems and H-systems. Derivation of predefined kinetic equation for bi-uni reactions deals with ordered and random order bi-uni mechanism. User-defined situations represent which equation to be appropriate for any sort of reaction and how to make sure unit reliability of the model.

\section{Result and discussion}

\subsection{Description of the model}

The created model is considered to simulate the mechanism of inactivation of TSHR, TPO, and NIS by known therapeutic drug PTU and regulation of thyroid hormone secretion. It has already been exercised that a small molecule antagonist may be used as a lead compound with higher affinity with therapeutic potential targeting TSHR for treatment of TSHR-mediated hyperthyroidism including Graves' disease (Neumann et al. 2008). The model was also used to simulate the mechanism of inhibition of over production of thyroid hormone by not letting TPO to convert iodide to iodine, as PTU binds to TPO and inactivates its regular pathways. In fact, PTU inhibits the production of fresh thyroid hormones (Ferreira et al. 2003; Taurog and Dorris 1989). The constructed model and Kinetics Equation for the model are displayed in Figs. 2, 3a, b and Table 1, respectively.
Leptin is a protein hormone that plays a significant role in regulating energy intake and energy outflow, including appetite and metabolism. It interacts with six categories of receptors (Ob-Ra-Ob-Rf, or LepRa-LepRf) which are encoded by only single gene, Leptin Receptor (LEPR) (Brennan and Mantzoros 2006). Leptin binds to the ObRb receptor of TRH neuron. It activates TRH gene expression. During neural inputs TRH is released in the hypothalamus hypophysial portal system and targets the pituitary gland. It binds to the TRHR of pituitary thyrotrophic cells and activates TSH gene expression. TSH is released into the blood and targets the TSHR of thyroid gland and activates a signaling cascade reaction.TSH binds with TSHR, and GTP is converted into GDP. TSHR detached G-protein which activates adenylate cyclase and converts ATP into c-AMP which later activates protein kinase-A (PKA). PKA transports into the nucleus, where it phosphorylates cAMP response element-binding (CREB). CREB binds to the promoter site of the thyroglobulin (TG) gene and regulates thyroglobulin gene expression (García-Jimenez and Santisteban 2007). TG is stored into the lumen of thyroid follicular cells. Iodine is transported to thyroid cell by NIS and finally into the lumen of thyroid follicular cells, where it is oxidized by TPO. Iodine is oxidized by TPO, and TG accumulates into the thyroid follicular cells. Tyrosine residue of TG is coupled with oxidized iodine and form monoiodothyronine (MIT) and diiodothyronine (DIT). MIT is formed by coupling of one iodine molecule with tyrosine residue of TG whereas DIT is formed by two iodine molecule coupled with tyrosine residue of TG. MIT and DIT are synthesized in the lumen of thyroid follicular cells and transported to thyroid cell, where one MIT is coupled with one DIT and forms $\mathrm{T}_{3}$. Two DITs are coupled and forms $\mathrm{T}_{4}$. Mostly, $\mathrm{T}_{4}$ is converted into the $\mathrm{T}_{3}$ by deiodinase enzyme. $T_{3}$ and $T_{4}$ are released into blood vascular system which later binds to Thyroid Receptor $\alpha$ (TR- $\alpha$ ) and Thyroid Receptor $\beta$ (TR- $\beta$ ), and modulate several gene expression (Miot et al. 2010).

The model represents the framework of proteins, gene, RNA, enzymes, products, and reactions involved in the TPO inactivation phenomenon. Specifically, it consists of 8 proteins, 1 gene, 1 RNA, 1 drug, 3 generic molecule, 3 ion entities, and the following reactions: 12 state transitions, one of this catalyzed by the PTU drug, 1 transport, 1 transcription, and 1 translation (Supplementary Table 1). In proposed model for drug targeting TPO, 15 reactions are involved. re1, re 4 , re 8 , re 12 , re $14-16$, re $20-22$, and re 25 are defined with Michaelis Constant. Substrate catalytic rate constant for TPO (Kcat) is used for species 20 in reaction re 8 . Half saturation constant and Hill coefficient for species DNATG gene in re 10 and association constant of reaction re 23 are defined, respectively, as drug participates for the inactivation of TPO enzyme at this stage. 


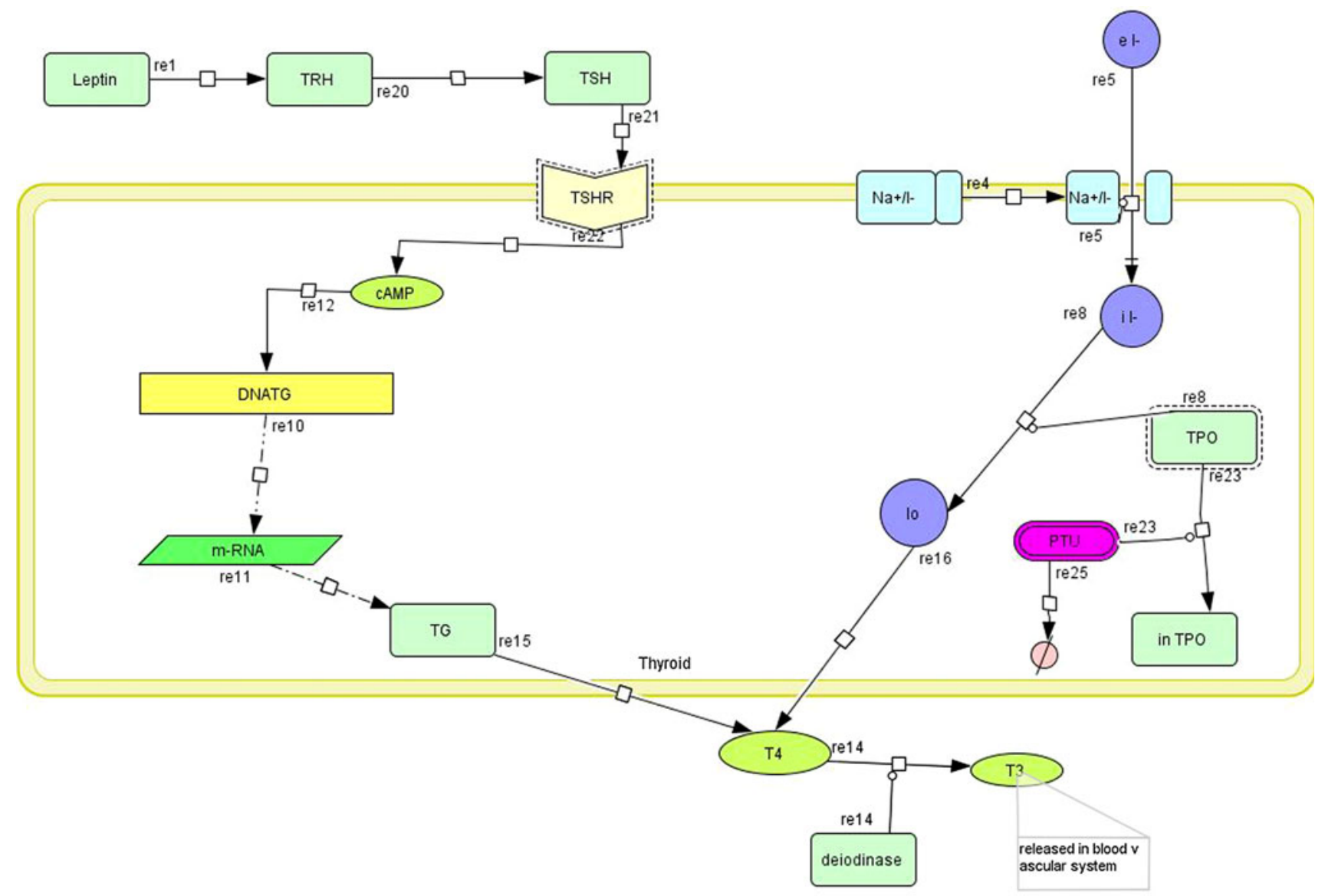

Fig. 2 Representation of pathway connecting protein, gene, mRNA, metabolites, enzyme and drug effect on thyroid hormone secretion for TPO analysis depicted in various colors such as protein $\rightarrow$ slight

Drug used for inactivation of TPO, predicting the variation pattern of thyroid hormones secretion as well as observing its effect on other species involved in pathway are given in Supplementary Table 2 .

Molecular species, entity values as well as corresponding rate kinetics of TSHR and NIS are given in Supplementary Tables 3-8. Different symbols and reactions are depicted in supplementary Fig. 1.

\subsection{Simulation analysis of the constructed model}

This study explains the outcome of an integrated approach to model the observable fact of modulating behavior of autoimmune disorder hyperthyroidism at molecular level with company of therapeutic drugs. This could be useful for understanding the dynamics involved for the modulation of thyroid hormone secretion for diverse targets. Further, it can be used to develop pharmacological approach to conquer its reoccurrence and up and down regulation.

Actual values for each molecular species have not been set due to its non-availability of experimental data for an green, active receptor $\rightarrow$ slight yellow with dotted line, gene $\rightarrow$ yellow, mRNA $\rightarrow$ green, PTU $\rightarrow$ dark pink, simple molecule $\rightarrow$ purple, ion-channel $\rightarrow$ slightly blue

individual cell. Simulation study can give an idea to analyze the modulating behavior of key species in the presence and absence of therapeutic ligand molecule for a particular ailment. Effects of TPO during thyroid hormone synthesis and inactivation are predicted in the presence of drug at the molecular level (Fig. 2).

In the absence of quantitative data of an individual cell, it is not easy to estimate the relationship between external and internal species. So, only internal ratios active among reactants or their fluxes are determined. Therefore, quantity is occupied in terms of amounts, to confirm their existence or their non-existence. For example, for the gene class, it cannot be described as concentration, supposing the gene as constant, and set each one equal to a unit of amount. All the molecular species are considered as variable species except few. Variable drug amount is considered for inactivation of TPO ranged from 0 to 3.0. Amount of species are set at $0,0.5,1$, and 2 according to their activation and inactivation state. For example, TPO is highly active in the case of hyperthyroidism so it is set at 2 . TPO, $\mathrm{T}_{4}$, deiodinase, are set to equal 2 due to the highly expressed 
Fig. 3 a Map representation of the model for inactivation of TSHR $\rightarrow$ light yellow in the presence of drug $\rightarrow$ pink color, Protein $\rightarrow$ light green, gene $\rightarrow$ yellow,

m-RNA $\rightarrow$ green, ion channel $\rightarrow$ light blue, simple molecule $\rightarrow$ purple b Integrated pathway map representation of NIS targeted by drug $\rightarrow$ pink color

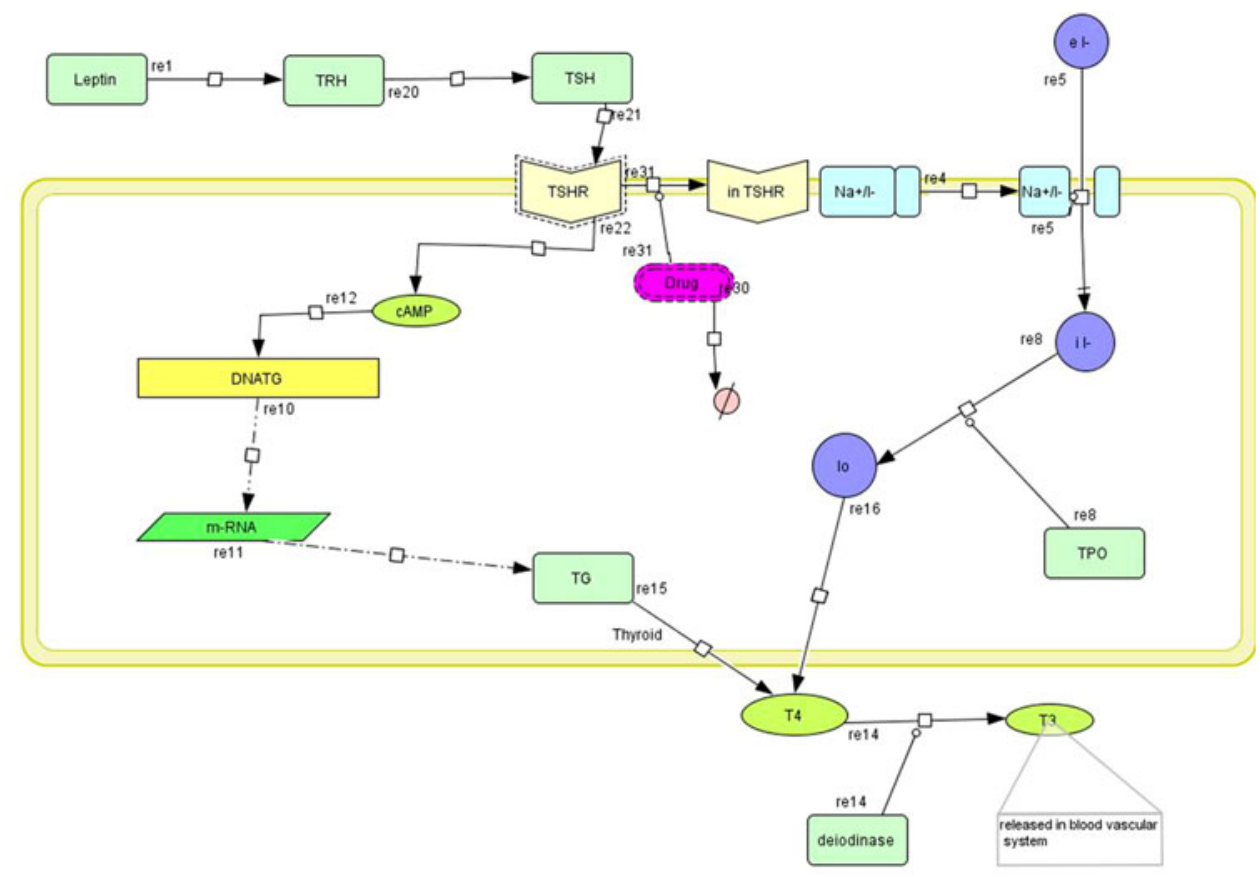

(a)

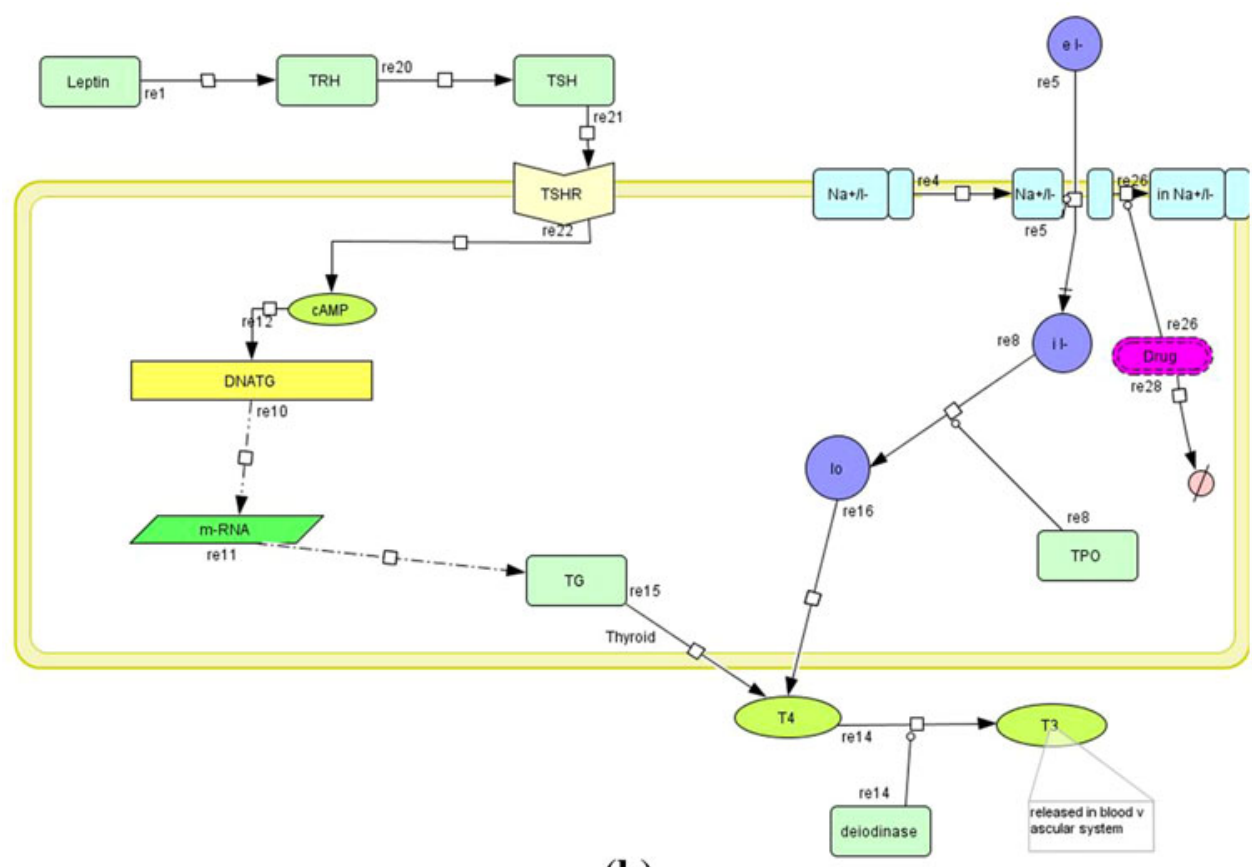

(b)

nature. The values of some species are set equal to 1 because these values signify basal amounts to certify the instigation of the gene and its relative expression. Amount of gene is set to 1 , because in cell a gene is all the time found even it is not expressed. Leptin, TSHR, T3 are set to equal 1 due to its basal amount for activation of other target. Some species are set at zero amounts as they do not express in the beginning. Some amounts are fixed at zero because initially they are not expressed for example ions, inactive TPO, degrades molecule. Regulation of gene expression is essential to permit a cell to make the gene products it wants when it wants them; consecutively, this provides cells the flexibility to acclimatize to variable surroundings. So, the transcript amount is more significant rather than the presence or absence of gene. TG m-RNA is highly expressed in the hyperthyroidism fixed two. NIS, 
Table 1 Details of kinetics equations for the model depicting drug targeting TPO enzyme

\begin{tabular}{|c|c|c|}
\hline S. no. & Reactant converted to product & Kinetics equations \\
\hline 1. & Leptin $\rightarrow$ TRH & vmax_re1 × Leptin/(kmc_re1_Leptin + Leptin) \\
\hline 2. & $\mathrm{TRH} \rightarrow \mathrm{TSH}$ & vmax_re20 × TRH/(kmc_re20_TRH + TRH) \\
\hline 3. & $\mathrm{TSH} \rightarrow \mathrm{TSHR}$ & vmax_re21 × TSH/(kmc_re21_TSH + TSH) \\
\hline 4. & $\mathrm{TSHR} \rightarrow \mathrm{cAMP}$ & vmax_re22 × TSHR/(kmc_re22_TSHR + TSHR) \\
\hline 5. & $\mathrm{cAMP} \rightarrow$ DNATG & vmax_re12 × cAMP/(kmc_re12_cAMP + cAMP) \\
\hline 6. & DNATG $\rightarrow$ m-RNA & $\begin{array}{l}\text { vmax_re10 } \times[\text { DNATG ^ ^hic_re10_DNATG/(DNATG } \\
\text { ^hic_re10_DNATG + ksp_re10_DNATG ^hic_re10_DNATG)] }\end{array}$ \\
\hline 7. & $\mathrm{~m}-\mathrm{RNA} \rightarrow \mathrm{TG}$ & $\begin{array}{l}\text { vmax_re11 } \times\left[\mathrm{m}-\mathrm{RNA} \wedge^{\wedge} \mathrm{hic} \_r e 11 \text { m-RNA/(m-RNA ^hic_re11_m-RNA + }\right. \\
\text { ksp_re11_s m-RNA ^hic_re11_m-RNA)] }\end{array}$ \\
\hline 8. & $\mathrm{Na}^{+} / \mathrm{I}^{-} \rightarrow$ Active $\mathrm{Na}^{+} / \mathrm{I}^{-}$ & vmax_re4 $\times$Na $+/$I-/(kmc_re4_Na $+/ \mathrm{I}-+\mathrm{Na}+/ \mathrm{I}-)$ \\
\hline 9. & Active TPO $\rightarrow$ Inactive TPO catalyzed by PTU & kass_re23_Drug $\times$ Active TSHR $\times$ Drug $\times \mathrm{c} 1$ \\
\hline 10. & $\mathrm{eI}-\rightarrow \mathrm{iI}-$ & vmax_re5 $\times$ eI-/(kmc_re5_eI- + eI-) \\
\hline 11. & iI $-\rightarrow$ Io catalyzed by TPO & S8 $\times$ [kcat_re8_TPO $\times$ iI-/(kmc_re8_iI-_TPO + iI- $)]$ \\
\hline 12. & $\mathrm{TG} \rightarrow \mathrm{T}_{4}$ & vmax_re15 × TG/(kmc_re15_TG + TG) \\
\hline 13. & Io $\rightarrow \mathrm{T}_{4}$ & vmax_re16 × Io/(kmc_re16_Io + Io) \\
\hline 14. & $\mathrm{~T}_{4} \rightarrow \mathrm{T}_{3}$ catalyzed by deiodinase & $\mathrm{s} 27 \times\left[\right.$ kcat_re14_deiodinase $\times \mathrm{T}_{4} /\left(\mathrm{kmc}\right.$ _re14_T $\mathrm{T}_{4}$ deiodinase $\left.\left.+\mathrm{T}_{4}\right)\right]$ \\
\hline 15. & Drug $\rightarrow$ Degrade & vmax_re25 $\times$ Drug $\times$ c1/(kmc_re25_Drug + Drug $\times \mathrm{c} 1)$ \\
\hline
\end{tabular}

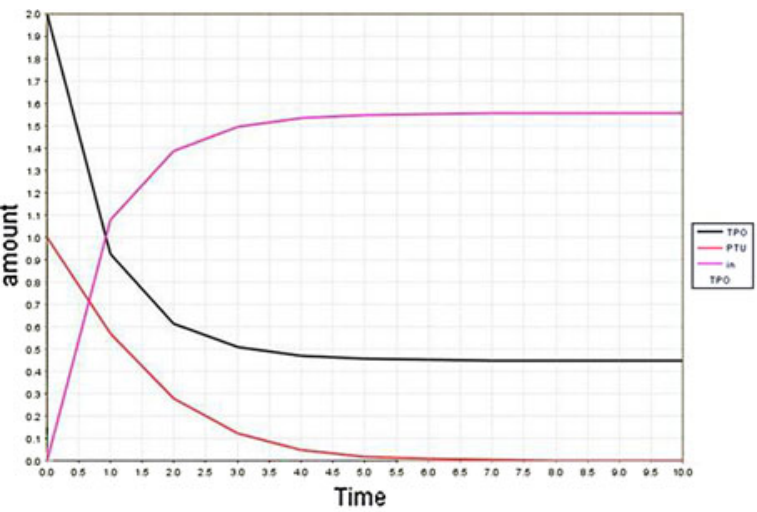

(a)

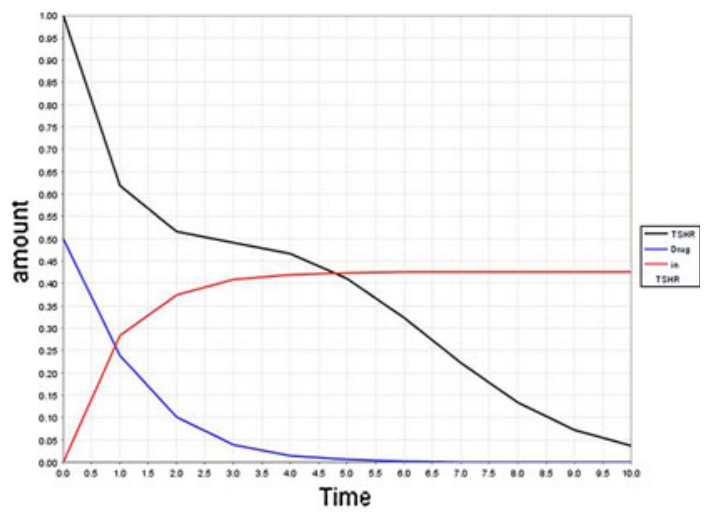

(b)

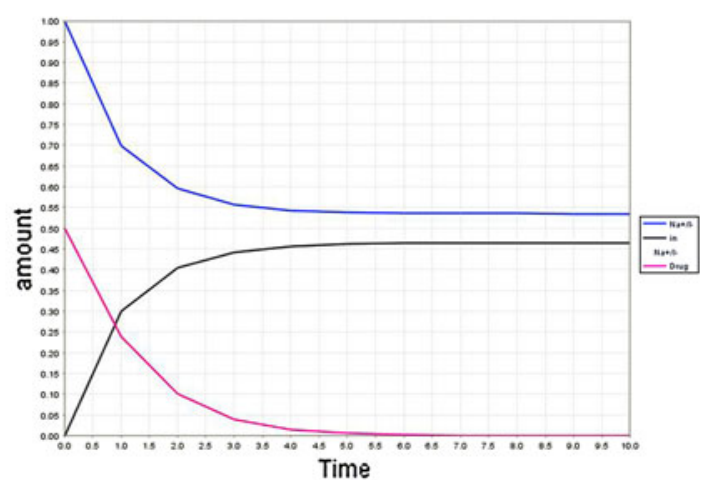

(c)

Fig. 4 Simulation curve for a active and Inactive TPO (black color $\rightarrow$ active TPO, red color $\rightarrow$ PTU and pink $\rightarrow$ inactive TPO) b active and inactive TSHR (black color $\rightarrow$ TSHR, red color $\rightarrow$ inactive TSHR, and blue color $\rightarrow$ drug) $\mathbf{c}$ active and inactive NIS in the presence of drug (black color $\rightarrow$ inactive NIS, blue color $\rightarrow$ active NIS, and pink $\rightarrow$ inactive drug) 


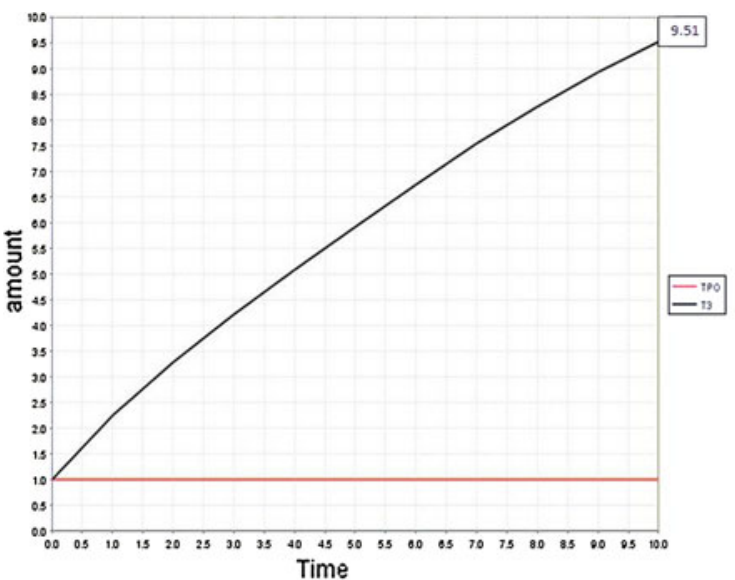

(a)

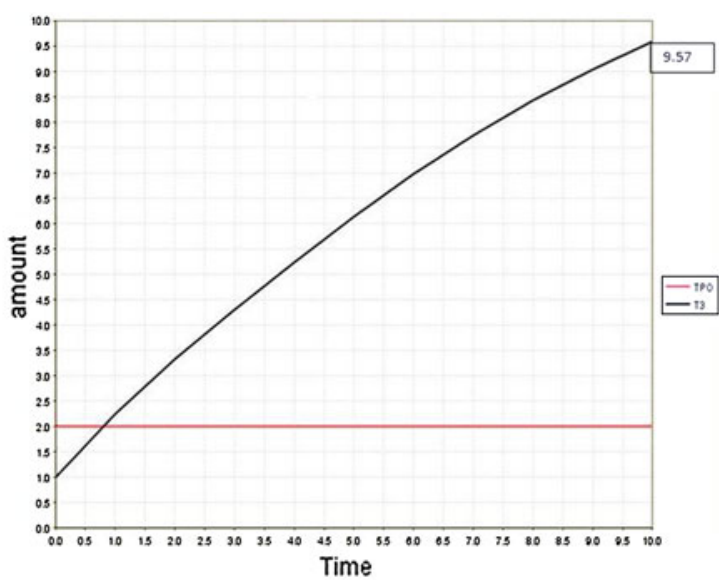

(b)

Fig. 5 Dynamic behavior analysis of $\mathrm{T}_{3}$ hormone a TPO amount is set at $1.0 \mathbf{b}$ TPO amount is set at 2.0

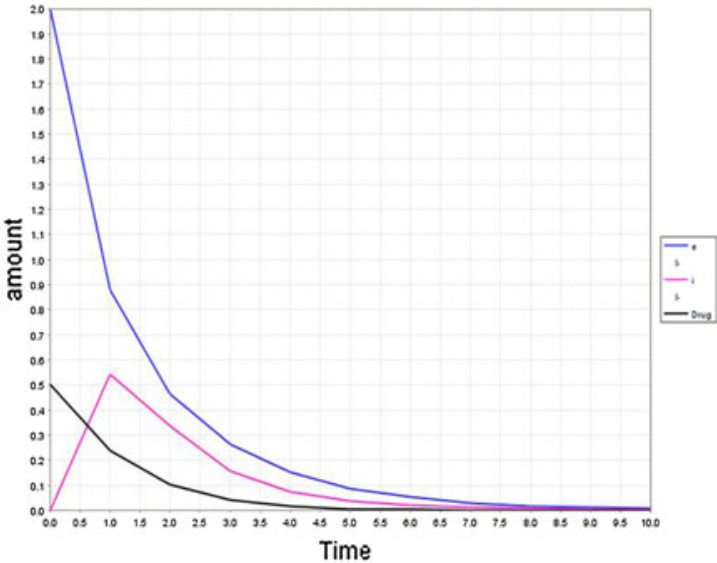

(a)

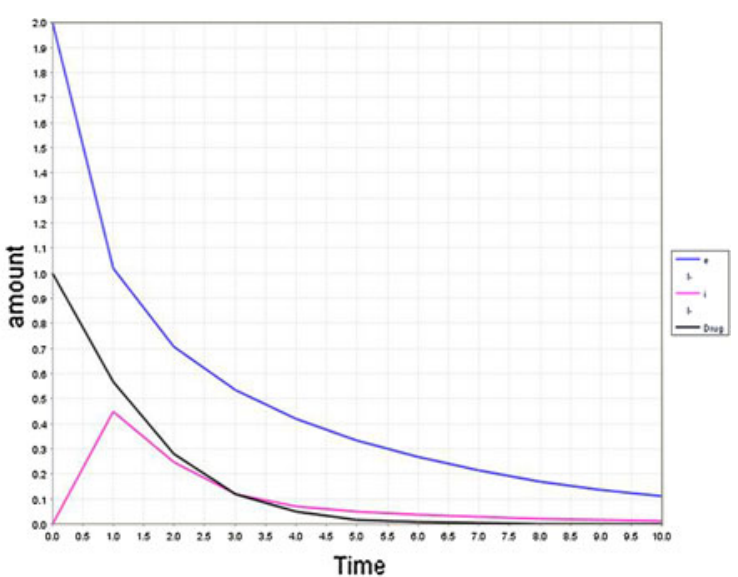

(b)

Fig. 6 Simulation result to prove inactivation of NIS to iodine transportation a at 0.5 drug concentration and $\mathbf{b}$ at 1.0 drug concentration

Iodine, and $\mathrm{T}_{3}$ are assigned 1 (Supplementary Table 1). The dynamic behaviors of different species are visualized during simulation with courses of time. The detailed values of drug targeting TPO and NIS are given in supplementary tables 3 and 6 . So, these results are meaningful for three targets which have been used in this study.

Variation of TPO pattern with respect to drug along with active and inactive (TSHR, NIS) are revealed in Fig. 4. The outcome of drug occurrence is obvious, because active TPO enzyme amount rapidly drops off in about two units of simulation time and turns into inactive TPO. $\mathrm{T}_{3}$ is highly expressed in about ten units of the time scale as shown in Fig. 5a, b. Drug amount when interacts with active TPO enzyme controls the modulation behavior of $\mathrm{T}_{3}$ hormone secretion. When one unit of drug is provided, inactivation of TPO is rapidly augmented from 0 to 1.5 , and active TPO is speedily decreased from 2 to 0.55 in ten units of simulation time revealed in Fig. 4a. Similarly, the curve simulations of TSHR and NIS have been performed and followed the similar pattern as in the case of TPO simulation. The inactive TSHR and NIS amounts rise while functional TSHR and NIS lessen with the passage of time. The drug amount is increased and set equal to 0.5 . The drug is showing its effect, because 0.5 amount of drug inactivates the TSHR and gives the evidence of its presence. Drug is also decreased in a unit of time. When 0.5 unit of drug is added into the biochemical relationship, inactivation of TSHR is quickly increased from 0 to 0.40 , and active TSHR is quickly decreased and settled down from 1 to 0.00 in ten units of simulation time as depicted in Fig. 4b. At 0.5 amount of drug, inactivation of NIS is quickly increased from 0 to 0.45 and active NIS is quickly decreased and becomes stationary from 1 to 0.55 in ten units of simulation time as displayed in Fig. 4c.

In reality, few initial parameters were customized in line to confirm how the curves alter and if the models respond 


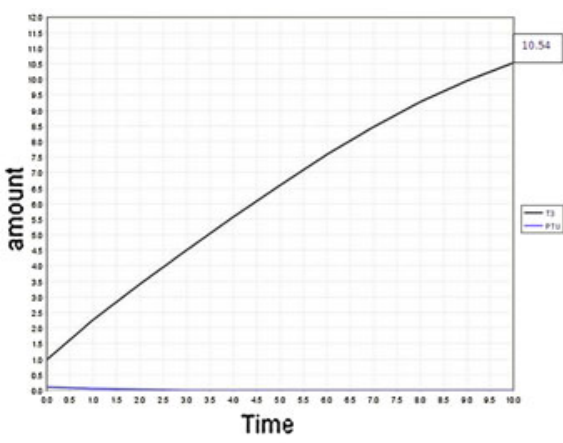

(a)

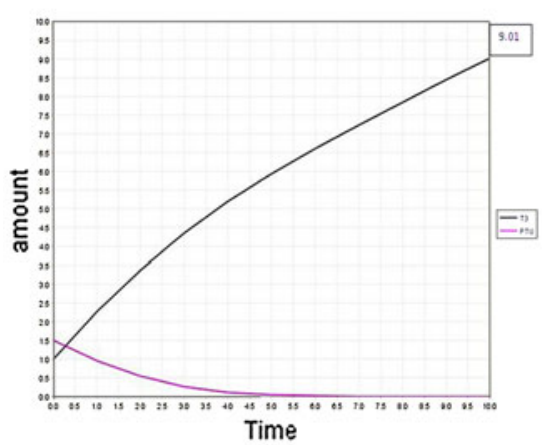

(d)

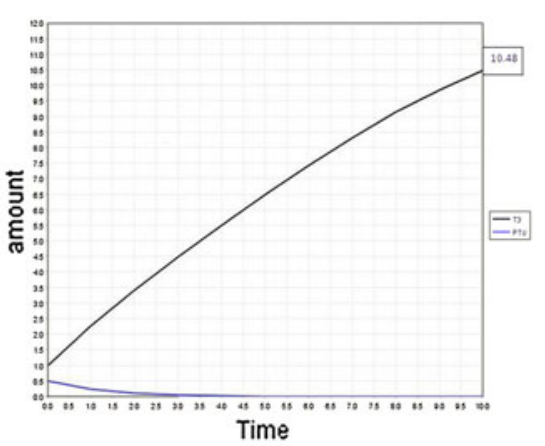

(b)

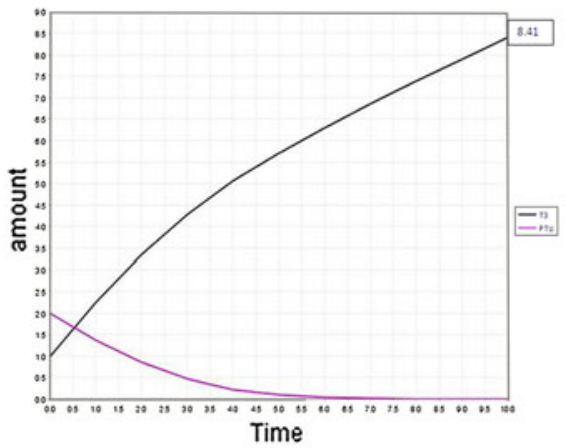

(e)

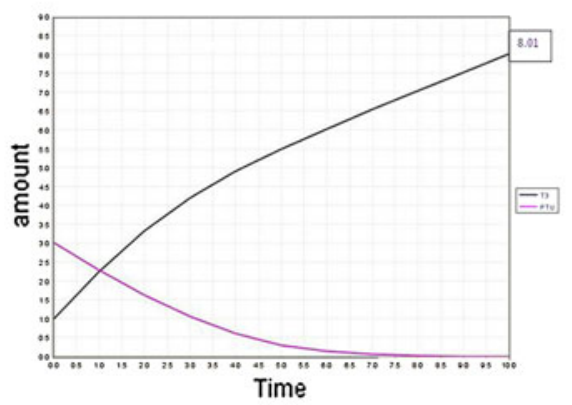

(g)

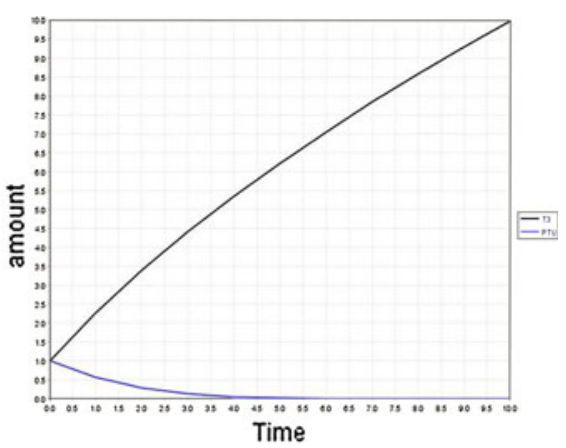

(c)

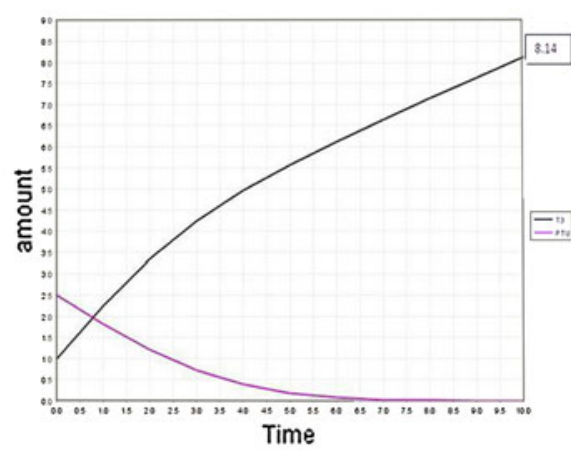

(f)

Fig. 7 Dynamic behavior analysis of drug against TPO target with altered amount of drugs a 0.1 b 0.5 c 1.0 d 1.5 e 2.0 f 2.5 and g 3.0 for analysis and its effect on systemic behavior

compatible to cellular mechanism. However, this means that the PTU likeness for its cellular enzyme should not be extremely high.

The model has also perturbed with altered drug quantity to confirm if it acts in response perfectly to perturbations. Actually, one can readily control the altered amounts of drug to modulate the cellular expression of TPO in proportion as well as $\mathrm{T}_{3}$ synthesis. The rate kinetics of thyroid hormone rely on the presence of TPO enzymes, TSHR, NIS and deiodinase are robustly subjected by the quantity of antithyroid drug that promote their inactivation and expression, as revealed in Fig. 6. A high quantity of antithyroid drug causes a speedy inactivation of the TPO, TSHR, and NIS. This momentarily prevents $\mathrm{T}_{3}$ synthesis that is continued only when the drugs get metabolized completely. In addition, this result divulges a significant phase of latency that can be used for novel pharmacological advancement.

The action of PTU is poor, progression of inactivation is slower, and growth curve of TPO amount is not defined by an immediate stop but by a gradual decrease, as depicted in Fig. 4a. TPO triggers response of the cell for thyroid hormone secretion after binding with drug. The secretion of $\mathrm{T}_{3}$ hormone depends on the availability of TPO amount. As the TPO expression increases, $\mathrm{T}_{3}$ production enhanced. Simulation study exhibits that perturbation is due to a little amount of drug that leads to $\mathrm{T}_{3}$ hormone is able to cover up rapidly the right amount. The target is not competent to instantly persuade its utilization even the cell perturbation takes due to high amount of PTU. This highlights the 


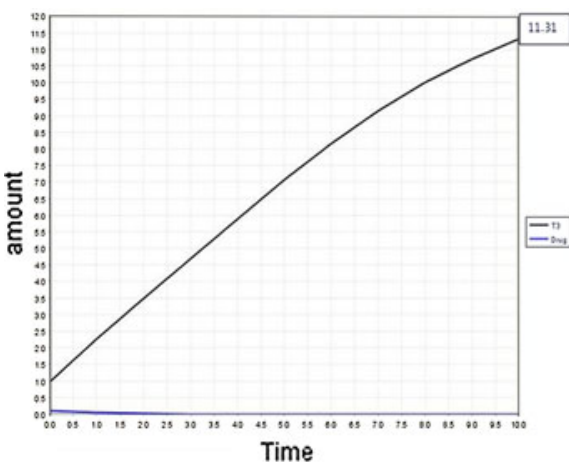

(a)

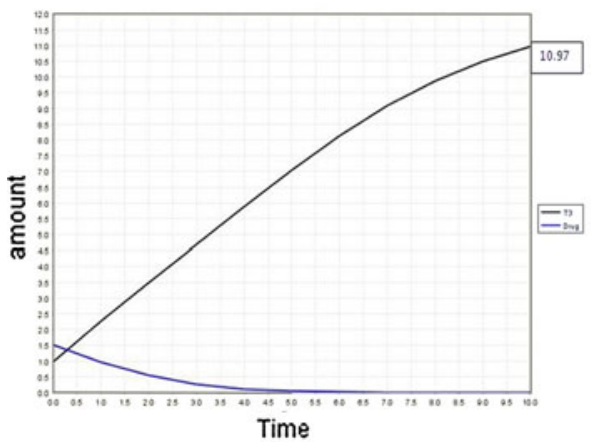

(d)

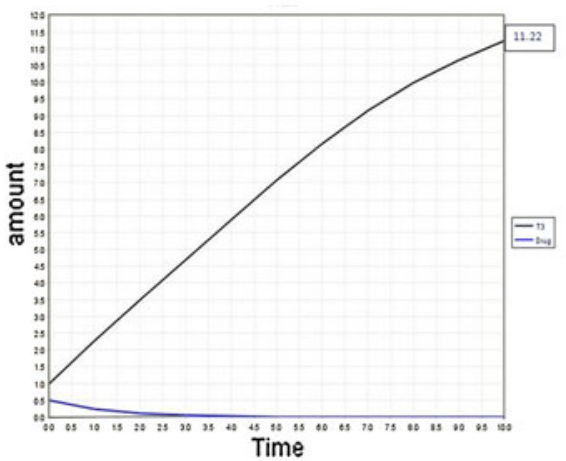

(b)

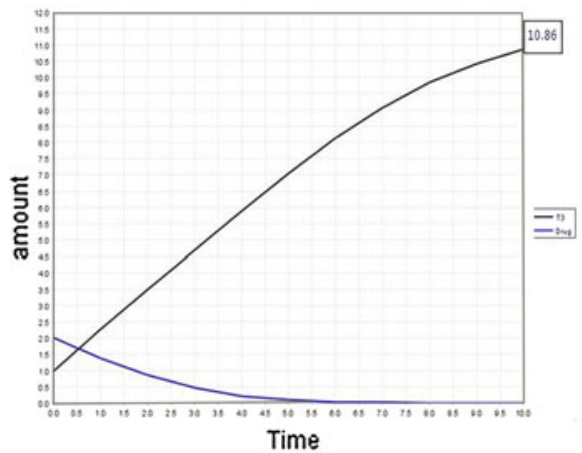

(e)

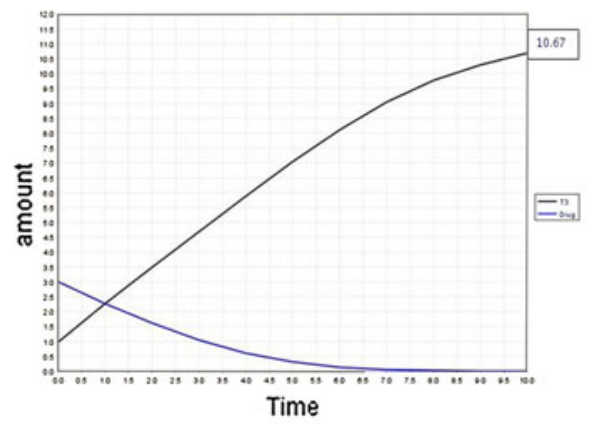

(g)

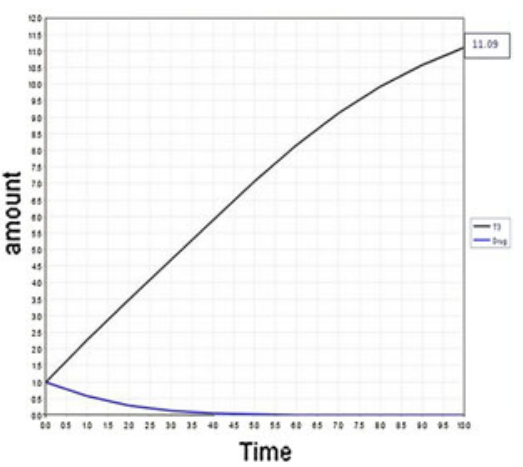

(c)

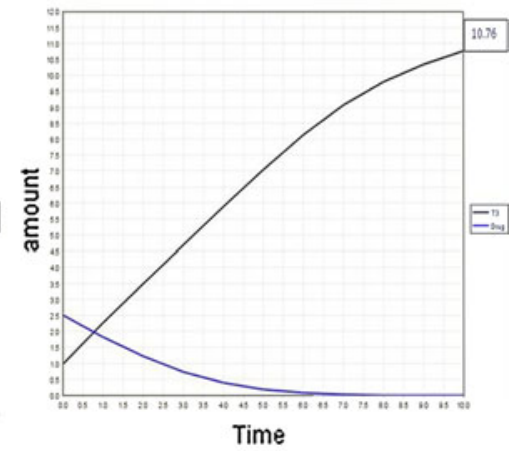

(f)

Fig. 8 The analysis of dynamic behavior against TSHR to simulate $T_{3}$ expression a 0.1 b 0.5 c 1.0 d 1.5 e 2.0 f 2.5 and g 3.0

correlation between efficacy of the treatment and doses used. Moreover, fluxes of all RNA species were also examined during this study.

TPO facilitates the catalysis of iodine. Inactivation of TPO leads to the decrease of the catalysis of iodine and amount of thyroid hormones secretion. Thyroid hormone synthesis increases with TPO amount. Figure 5a depicts that amount of extracellular TPO is defined as one, $\mathrm{T}_{3}$ amount is increased and settled down at 9.51 in ten units of simulation time. If TPO amount is increased and set to 2 then $\mathrm{T}_{3}$ amount increases and reaches 9.57. This can be inferred that TPO amount is in monotonic relationship with the thyroid hormone synthesis, as displayed in Fig. 5a, b. In hyperthyroidism, the activity of TPO gets enhanced that leads to high secretion of $\mathrm{T}_{3}$ and $\mathrm{T}_{4}$ hormone.
NIS facilitates transportation of iodine from extracellular to intracellular. Simulation of NIS inactivation by drug affects iodine transportation. Amounts of extracellular and intracellular iodine are set to 2 and 0 , respectively. Elevation in the level of drug from 0.5 to 1.0 results in inactivation of NIS which causes decrease in iodine amount at intracellular compartment. The amount of drug increased and settled down at 1.0 and iodine amount is drop off revealing the effect of drug against iodine transportation as depicted in Fig. 6. Intracellular iodine amount is slightly increased approximately 0.42 due to effect of drug. So, here the drug also proves the NIS inactivation.

Dynamic simulations behavior with altered quantity of drug shown in Fig. 7 illustrate that action of TPO curves have the same opinion with the natural prospect. It predicts 
the amount of $\mathrm{T}_{3}$ against the drug effect. $\mathrm{T}_{3}$ gets settled down at 10.54 in ten units of simulation time at 0.1 amount of drug. Amount of drug at different amounts such as 0.5 , $1.0,1.5,2.0,2.5$, and 3.0 causes decline in synthesis of $\mathrm{T}_{3}$ production with slight differences and reached to 10.48 , $10.0,9.01,8.41,8.14$, and 8.01 , respectively. This suggests that increase in drug amount lowers down the level of $T_{3}$ and $\mathrm{T}_{4}$.

Different amounts of drug have been taken to find out its effect with respect to time targeting TSHR. At 0.1 unit of drug amount, $\mathrm{T}_{3}$ synthesis reached to 11.31 in ten units of simulation time. To investigate the effect of drug amount, the quantity of drug is increased in 0.5 unit, and all remaining components are fixed in same quantity. Amount of drug is amplified to 1.0 , reason is $\mathrm{T}_{3}$ synthesis lessens from 11.31 to 11.09 . Slight variation was observed in the assembly thyroid hormone molecule at perturbed drug amount. At 1.5, 2, 2.5, and 3 drug amounts, $\mathrm{T}_{3}$ production were found to be $10.97,10.86,10.76$, and 10.67 , respectively (Fig. $8 \mathrm{~d}-\mathrm{g}$ ). This proves that the action of drug in relation to target is very effective for modulation of thyroid hormone production with slight variation.

Different amounts of drug are used for measuring effect of $\mathrm{T}_{3}$ production targeting NIS. At 0.1 amount drug, $\mathrm{T}_{3}$ gets fixed at 9.60 in ten unit of simulation time and to investigate the effects of drug at augmented level from 0.1 to 0.5 keeping remaining components in same quantity. Amount of drug is amplified and set equal to 1.0 which lowers down $T_{3}$ production from 9.60 to 9.41 . The variations in the simulation curve of thyroid hormone production are observed as 9.03, 8.64, 8.39, and 8.25 at drug amounts 1.5, 2.0, 2.5, and 3.0, respectively. The association between drug and target is proved by lowering down the synthesis thyroid hormone in hyper state. It is evident that drug targeting NIS leads to less production of $\mathrm{T}_{3}$ as compared to TSHR (supplementary Fig. 2).

Biologically small active molecules have been verified previously for the analysis of biological pathways modulation for thyroid hormone receptor (Schapira et al. 2003). In this study, we have rebuilt and analyzed systemic interactions of drugs effect on whole model for progression of thyroid disorder. This integrated approach shows that computational demonstration can construct and explain precisely the complete observable fact of antithyroid drugs at metabolic level. The constructed technical model describes the biochemical relationship of different molecular species and effect of drug in different unit time. This type of in silico finding provides a valuable hypothesis and mimics by the simulation analysis as in vitro test. The study exhibits that the cellular reaction depends on the effective quantity of antithyroid drugs inside and outside the cell. TPO is a well-known molecular target in the case of hyperthyroidism. It gives a good effect in that biochemical relationship and proves its evidence to inactivate the TPO and decrease the level of oxidized iodine and $T_{3}$. As a result, the understanding of the integrated metabolic behavior can be valuable to develop novel therapeutic approaches to control the administration of antagonist antithyroid drugs for examining the mechanism on the interaction of drugs with various molecular targets.

This study helps us to analyze the antithyroid peroxidase drugs with perturbed effect, which is mostly linked with Hashimoto's Thyroiditis. Thus, the constructed model can be useful not only for hyperthyroidism but also for hypothyroidism disorder. It is suggested that an antagonist ligand reduces TSHR activation by thyroid stimulating antibodies (TsAbs) from people who are suffering with Graves' disease. Inactivation of TSHR declines the thyroglobulin gene expression by the arbitration of c-AMP and concentration of thyroid hormones. Moreover, it belongs to G Protein Coupled Receptor (GPCR) family (Sun et al. 2003) which found on surface of the cell membrane whereas thyroid receptor is a nuclear receptor. This means that targeting TSHR is less cumbersome as compared to thyroid receptor for drug molecules (Schapira et al. 2003) and makes the bioavailability of drug for TSHR as compare to thyroid receptor. Therefore, TSHR can be considered as a potential molecular therapeutic target in thyroid disorder.

NIS is non-thyroid-specific protein as its expression has been noticed in non-thyroidal tissues too. It has been confirmed that TSH, iodide, estrogen retinoic, cytokines, histones deacetylase inhibitors, thyroid transcription factor and thyroglobulin are keys factor that regulate the expression of NIS. Total loss of thyroid cell differentiation leads to low or zero NIS expression in thyroid cancer ultimately results in non-uptake of iodide molecule (Carvalho and Ferreira 2007). The pharmacokinetics and pharmacodynamics properties of PTU drug action given in drug bank (http://www.drugbank.ca/drugs/DB00550) support the validity of model. The constructed model can be useful after optimizing to analyse the effect of above factors.

\section{Conclusion}

TSHR was found as the most important therapeutic target as compared to TPO and NIS due to its occurrence on cell surface. Any biochemically active molecules do not easily cross the cell membrane; hence, targeting TSHR could be more encouraging than other targets.

The integrated immune system network is intricate, composed of myriad inter and intra contacts that evade absolute perceptive. It provides prolific platform for the extrication of these intertwined vagueness with assistance 
insight gained from synergistic effect of experimental studies, hypothesis, theory, and computational modeling. This approach can be useful for experimental design, interpretation, and comparative study of normal and diseased pathway. Noticeably, formulating, designing, modeling, and simulating an experiment from in silico point of view is easier than wet lab. By extending the idea derived here, it is obvious that concurrent multiple drugs' effect with perturbed amount could be useful to observe the robustness of the designed model. A number of undiscovered effects of drugs with their perturbed amount to its corresponding targets can be predicted. Nevertheless, it seems to be essential to examine more conditions that imitate realistic stress situation in an attempt to find out which method need to be developed to cope with their usual environment. In terms of biomedical significance, it is assumed that the availability of a constructed metabolic model can further speed up the research of non-communicable and communicable diseases. Drug discovery processes depend on decision making and such type of model can be useful in potential drug target identification, validation, and interpretation of result at cellular and system level.

\section{References}

Autiero I, Costantini S, Colonna G (2009) Modeling of the bacterial mechanism of methicillin-resistance by a systems biology approach. PLoS ONE 4(7):e6226

Bortolussi L, Policriti A (2012) Studying cancer-cell populations by programmable models of networks. Netw Model Anal Health Inform Bioinforma 1:117-133

Brennan AM, Mantzoros CS (2006) Drug Insight: the role of leptin in human physiology and pathophysiology-emerging clinical applications. Nat Clin Pract Endocrinol Metab 2(6):318-327

Brent GA (2010) Environmental exposures and autoimmune thyroid disease. Thyroid 20(7):755-761

Butcher EC, Berg EL, Kunkel EJ (2004) Systems biology in drug discovery. Nat Biotechnol 22:1253-1259

Calzone L, Gelay A, Zinovyev A, Radvanyi F, Barillot E (2008) A comprehensive modular map of molecular interactions in RB/ E2F pathway. Mol Syst Biol 4:173

Caron E, Ghosh S, Matsuoka Y, Ashton-Beaucage D, Therrien M, Lemieux S, Perreault C, Roux PP, Kitano H (2010) A comprehensive map of the mTOR signaling network. Mol Syst Biol 6:453

Carvalho DP, Ferreira AC (2007) The importance of sodium/iodide symporter (NIS) for thyroid cancer management. Arq Bras Endocrinol Metabol 51(5):672-682

Chardès T, Chapal N, Bresson D, Bès C, Giudicelli V, Lefranc MP, Peraldi-Roux S (2002) The human anti-thyroid peroxidase autoantibody repertoire in Graves' and Hashimoto's autoimmune thyroid diseases. Immunogenetics 54(3):141-157

Chen CR, McLachlan SM, Rapoport B (2009) A monoclonal antibody with Thyrotropin (TSH) receptor inverse agonist and TSH antagonist activities binds to the receptor hinge region as well as to the leucine-rich domain. Endocrinology 150(7):3401-3408
Chu JY, Lee LT, Lai CH, Vaudry H, Chan YS, Yung WH, Chow BK (2009) Secretin as a neurohypophysial factor regulating body water homeostasis. Proc Natl Acad Sci USA 106(37): 15961-15966

Davies TF, Latif R, Yin X (2012) New genetic insights from autoimmune thyroid disease. J Thyroid Res 2012:623852

Diamanti-Kandarakis E, Bourguignon JP, Giudice LC, Hauser R, Prins GS, Soto AM, Zoeller RT, Gore AC (2009) Endocrinedisrupting chemicals: an Endocrine Society scientific statement. Endocr Rev 30(4):293-342

Dohán O, De la Vieja A, Paroder V, Riedel C, Artani M, Reed M, Ginter CS, Carrasco N (2003) The sodium/iodide Symporter (NIS): characterization, regulation, and medical significance. Endocr Rev 24(1):48-77

Dräger A, Hassis N, Supper J, Schröder A, Zell A (2008) SBMLsqueezer: a Cell Designer plug-into generate kinetic rate equations for biochemical networks. BMC Syst Biol 2:39

Eduardo AN (2010) Regulation of the Hypothalamic Thyrotropin Releasing Hormone (TRH) neuron by neuronal and peripheral inputs. Front Neuroendocrinol 31(2):134-156

Farid NR, Szkudlinski MW (2004) Minireview: structural and functional evolution of the thyrotropin receptor. Endocrinology 145(9):4048-4057

Ferreira AC, de Carvalho Cardoso L, Rosenthal D, de Carvalho DP (2003) Thyroid Ca2+/NADPH-dependent $\mathrm{H}_{2} \mathrm{O}_{2}$ generation is partially inhibited by propylthiouracil and methimazole. Eur $\mathrm{J}$ Biochem 270(11):2363-2368

Funahashi A, Morohashi M, Tanimura N, Kitano H (2003) CellDesigner: a process diagram editor for gene-regulatory and biochemical networks. Biosilico 1:159-162

Funahashi A, Jouraku A, Matsuoka Y, Kitano H (2007) Integration of Cell Designer and SABIO-RK. In Silico Biol 7(Suppl 2):S81S90

Funahashi A, Matsuoka Y, Jouraku A, Morohashi M, Kikuchi N, Kitano H (2008) CellDesigner 3.5: a versatile modeling tool for biochemical networks. Proc IEEE 96(8):1254-1265

García-Jimenez C, Santisteban P (2007) TSH Signalling and Cancer. Arq Bras Endocrinol Metab 51(5):654-671

Gupta MK, Singh DB, Rath SK, Misra K (2012) Metabolic modeling and simulation analysis of thyroid disorder pathway. J Comput Sci Syst Biol 5:052-061. doi:10.4172/jcsb.1000090

Hollenberg AN (2008) The role of the thyrotropin-releasing hormone (TRH) neuron as a metabolic sensor. Thyroid 18(2):131-139

Hucka M, Finney A, Bornstein BJ, Keating SM, Shapiro BE, Matthews J, Kovitz BL, Schilstra MJ, Funahashi A, Doyle JC, Kitano H (2004) Evolving a lingua franca and associated software infrastructure for computational systems biology: the Systems Biology Markup Language (SBML) project. Syst Biol (Stevenage) 1(1):41-53

Ideker T, Galitski T, Hood L (2001) A new approach to decoding life: systems biology. Annu Rev Genomics Hum Genet 2:343-372

Kaizu K, Ghosh S, Matsuoka Y, Moriya H, Shimizu-Yoshida Y, Kitano H (2010) A comprehensive molecular interaction map of the budding yeast cell cycle. Mol Syst Biol 6:415

Kell DB (2006) Systems biology, metabolic modelling and metabolomics in drug discovery and development. Drug Discov Today 11(23-24): 1085-1092

Kessler J, Obinger C, Eales G (2008) Factors influencing the study of peroxidase-generated iodine species and implications for thyroglobulin synthesis. Thyroid 18(7):769-774

Kim PS, Levy D, Lee PP (2009) Modeling and simulation of the immune system as a self-regulating network. Methods Enzymol 467:79-109

Kitano H (2003) A graphical notation for biochemical networks. Biosilico 1:169-176 
Kitano H, Oda K (2006) Robustness trade-offs and host-microbial symbiosis in the immune system. Mol Syst Biol 2:2006-2022

Klieverik LP, Coomans CP, Endert E, Sauerwein HP, Havekes LM, Voshol PJ, Rensen PC, Romijn JA, Kalsbeek A, Fliers E (2009) Thyroid hormone effects on whole-body energy homeostasis and tissue-specific fatty acid uptake in vivo. Endocrinology 150(12):5639-5648

Klipp E, Liebermeister W (2006) Mathematical modeling of intracellular signaling pathways. BMC Neurosci 7:S10

Lehar J, Krueger A, Zimmermann G, Borisy A (2008) High-order combination effects and biological robustness. Mol Syst Biol $4: 215$

Liebermeister W, Uhlendorf J, Klipp E (2010) Modular rate laws for enzymatic reactions: thermodynamics, elasticities and implementation. Bioinformatics 26(12):1528-1534

McLachlan SM, Rapoport B (2000) Autoimmune response to the thyroid in humans: thyroid peroxidase-the common autoantigenic denominator. Int Rev Immunol 19(6):587-618

McLachlan SM, Rapoport B (2007) Thyroid peroxidase as an autoantigen. Thyroid 17(10):939-948

Mi H, Lazareva-Ulitsky B, Loo R, Kejariwal A, Vandergriff J, Rabkin S, Guo N, Muruganujan A, Doremieux O, Campbell MJ, Kitano H, Thomas PD (2005) The PANTHER database of protein families, subfamilies, functions and pathways. Nucleic Acids Res 33(Database issue):D284-D288

Miot F, Dupuy C, Dumont J, Rousset B (2010) Thyroid hormone synthesis and secretion. Thyroid disease manager. http://www. thyroidmanager.org/chapter/thyroid-hormone-synthesis-and-secr etion/. Accessed on 15 June 2012

Neumann S, Kleinau G, Costanzi S, Moore S, Jiang JK, Raaka BM, Thomas CJ, Krause G, Gershengorn MC (2008) A low-molecularweight antagonist for the human thyrotropin receptor with therapeutic potential for hyperthyroidism. Endocrinology 149(12):5945-5950

Neumann S, Raaka BM, Gershengorn MC (2009) Human TSH receptor ligands as pharmacological probes with potential clinical application. Expert Rev Endocrinol Metab 4(6):669

Neumann S, Huang W, Eliseeva E, Titus S, Thomas CJ, Gershengorn MC (2010) A small molecule inverse agonist for the human thyroid-stimulating hormone receptor. Endocrinology 151(7): 3454-3459

Oda K, Kitano H (2006) A comprehensive map of the toll-like receptor signaling network. Mol Syst Biol 2:2006-2015

Oda K, Matsuoka Y, Funahashi A, Kitano H (2005) A comprehensive pathway map of epidermal growth factor receptor signaling. Mol Syst Biol 1:2005-2010
Ohye H, Sugawara M (2010) Dual oxidase, hydrogen peroxide and thyroid diseases. Exp Biol Med (Maywood) 235(4):424-433

Riesco-Eizaguirre G, Santisteban P (2006) A perspective view of sodium iodide symporter research and its clinical implications. Eur J Endocrinol 155(4):495-512

Roy G, Mugesh G (2008) Selenium analogues of antithyroid drugsrecent developments. Chem Biodivers 5(3):414-439

Ruf J, Carayon P (2006) Structural and functional aspects of thyroid peroxidase. Arch Biochem Biophys 445(2):269-277

Schapira M, Raaka BM, Das S, Fan L, Totrov M, Zhou ZG, Wilson S, Abagyan R, Samuels HH (2003) Discovery of diverse thyroid hormone receptor antagonists by high-throughput docking. Proc Natl Acad Sci USA 100(12):7354-7359

Singh DB, Gupta MK, Kesharwani RK, Misra K (2013) Comparative docking and ADMET study of some curcumin derivatives and herbal congeners targeting b-amyloid. Netw Model Anal Health Inform Bioinforma. doi:10.1007/s13721-012-0021-7

Sun Y, Lu X, Gershengorn MC (2003) Thyrotropin-releasing hormone receptors-similarities and differences. J Mol Endocrinol 30(2):87-97

Swain M, Swain T, Mohanty BK (2005) Autoimmune thyroid disorders-an update. Indian J Clinic Biochem 20:9-17

Szkudlinski MW, FremontV Ronin C, Weintraub BD (2002) Thyroidstimulating hormone and thyroid-stimulating hormone receptor structure-function relationships. Physiol Rev 82:473-502

Taurog A, Dorris ML (1989) A reexamination of the proposed inactivation of thyroid peroxidase in the rat thyroid by propylthiouracil. Endocrinology 124(6):3038-3042

Vlase H, Weiss M, Graves PN, Davies TF (1998) Characterization of the murine immune response to the murine TSH receptor ectodomain: induction of hypothyroidism and TSH receptor antibodies. Clin Exp Immunol 113(1):111-118

Weetman AP (2003) Autoimmune thyroid disease: propagation and progression. Eur J Endocrinol 148:1-9

Wilding JP (2002) Neuropeptides and appetite control. Diabet Med 19:619-627

Wu G, Zhu L, Dent JE, Nardini C (2010) A comprehensive molecular interaction map for rheumatoid arthritis. PLoS ONE 5:e10137

Xiang Y, Fuhry D, Kaya K, Jin R, Catalyurek UV, Huang K (2012) Merging network patterns: a general framework to summarize biomedical network data. Netw Model Anal Health Inform Bioinforma 1:103-116 